\title{
Effects of Treadmill Exercise on Sexual Behavior and Reproductive Parameters in Chronically Stressed-Male Rats
}

\author{
Haluk KELESTIMUR ${ }^{1}$, Ozgur BULMUS ${ }^{2}$, Ihsan SERHATLIOGLU ${ }^{3}$, Zubeyde ERCAN ${ }^{4}$, \\ Seyma OZER KAYA ${ }^{5}$, Ahmet YARDIMCI ${ }^{1}$, Nazife ULKER $^{1}$, Emine KACAR ${ }^{1}$, Sinan \\ CANPOLAT ${ }^{1}$
}

${ }^{1}$ Department of Physiology, Faculty of Medicine, Firat University, Elazig, Turkey, ${ }^{2}$ Department of Physiotherapy and Rehabilitation, Faculty of Health Sciences, Balikesir University, Balikesir, Turkey, ${ }^{3}$ Department of Biophysics, Faculty of Medicine, Firat University, Elazig, Turkey, ${ }^{4}$ Department of Physiotherapy and Rehabilitation, Faculty of Health Sciences, Firat University, Elazig, Turkey, ${ }^{5}$ Department of Reproduction and Artificial Insemination, Faculty of Veterinary Medicine, Firat University, Elazig, Turkey

Received October 9, 2020

Accepted July 9, 2021

Epub Ahead of Print September 10, 2021

\section{Summary}

Exposure to chronic stress stimulates the hypothalamic-pituitaryadrenal (HPA) axis and then simultaneously inhibits hypothalamic-pituitary-gonadal axis (HPG) axis activity. The inhibition formed by the HPA axis is the main mechanism of action of stress on reproductive function. HPG axis activity is known to be changed by various factors, including exercise. Exercise has been found to have a number of positive effects on sexual behavior, reproductive hormones, and sperm parameters in studies with animal models for many years. The main aim of this study is to investigate the effects of chronic treadmill exercise on chronically stressed-male rats' sexual behavior, reproductive hormones, and sperm parameters. A total of 40 sexually adult male rats were randomly and equally divided into four groups as control, stress, exercise, and stress+exercise. Animals in the exercise group were subjected to the chronic treadmill exercise (moderate intensity) for 33 days with a periodic increase in speed and duration. Animals in the stress group were exposed to restraint stress for $1 \mathrm{~h}, 2 \mathrm{~h}$, and $3 \mathrm{~h}$ during the first, second and third 15 days respectively. Sexual behavior parameters, hormone measurements, and sperm parameters were evaluated. The main effects of chronic exercise on sexual behavior were centered on a significant increase in the ejaculation frequency (EF) in the stress+exercise group. Also, sperm concentration and motility in the stress group significantly decreased, and then sperm motility was improved by exercise in the stress+exercise group. In sum, our results show that chronic treadmill exercise may improve the adverse effects of chronic stress on sexual behavior and sperm parameters in male rats in terms of some parameters.

\section{Key words}

Treadmill exercise • Restraint stress • Sexual behavior • Sperm parameters $\bullet$ Hormones

\section{Corresponding author}

H. Kelestimur, Department of Physiology, Faculty of Medicine, Firat University, Elazig, TR23119, Turkey. E-mail: hkelestimur@firat.edu.tr

\section{Introduction}

Stress is a process that triggers systemic and behavioral responses associated with a series of physiological changes, leading to structural and functional abnormalities in many organs. Reproductive activity is one of the main functions that change and inactivate during the adaptive response to stress (Johnson et al. 1992). Especially, exposure to chronic stress results in hypothalamic-pituitary-adrenal (HPA) axis dysregulation, mood, and reproductive disorders (Bao et al. 2008, Florio et al. 2007). Several studies have 
shown that chronic stress causes morphological and functional changes in reproductive organs. It has detrimental effects on testis and various semen parameters including sperm concentration, sperm motility, and sperm morphology (Clarke et al. 1999, Demirci and Sahin 2019, Nordkap et al. 2016). In this sense, it has been revealed that the impairments in sperm production, decreased testosterone levels (García-Díaz et al. 2015, Hari Priya and Reddy 2012) and testicular weights were observed in rats exposed to chronic stress (Hari Priya and Reddy 2012, Rosmond and Björntorp 2000). Chronic restraint stress has been considered as one of the most commonly used stress-inducing models in rodents and produces detrimental effects in a variety of systems, including sexual dysfunction, such as those observed in humans (Bal et al. 2009). It has been reported that chronic restraint stress leads to suppression of testosterone secretion (Al-Damegh 2014), sexual motivation, and spermatogenesis (Almeida et al. 1998, Almeida et al. 2000a). Chronic restraint stress has been shown to cause delayed testicular maturation in male rats when mated. In addition, there is a 2-fold loss of preimplantation and post-implantation pregnancy formation in female rats (Almeida et al. 2000b). Male rats exposed to chronic stress have been shown to prolong intromission and ejaculation latency as an indicator of impaired sexual activity and show less ejaculation than control rats (Grønli et al. 2005).

Exercise has many physical and psychological beneficial effects on the organism. Exercise has been found to have significant improvements in erectile function, sexual confidence, sexual desire, sexual satisfaction, and overall sexual health (Lamina et al. 2009, Maio et al. 2010, Khoo et al. 2013). However, there is still important contradictory in how exercise affects sex hormone levels and spermatogenesis. For example, moderate-intensity exercise attenuates the negative effects of age or obesity on spermatogenesis (You et al. 2013, Joseph et al. 2014), increases male sex hormone levels (Sato and Lemitsu 2015), and improves male reproductive capacity (Rosety-Rodriguez et al. 2014, Gaskins et al. 2015). In contrast, prolonged, highfrequency, high-intensity endurance exercise has been found to reduce male sex hormone levels and decreases sperm concentration and motility in animals and humans (Maleki and Tartibian 2015). Despite several reports on the effects of stress stimuli on the reproductive system, the effect of exercise on reversing these effects is not fully understood. Therefore, this study aims to examine the potential effects of chronic treadmill exercise on sexual behavior, sperm parameters, specific hormone levels, and reproductive organ weights in adult male rats exposed to chronic restraint stress.

\section{Materials and Methods}

\section{Animals}

The experimental protocol was approved by the Animal Experimental Ethics Committee of Firat University (Elazig, Turkey), performed according to the Guide for the Care and Use of Laboratory Animals. Sexually experienced Sprague-Dawley male rats ( 3 months old, $n=40$ ) were obtained from the Firat University Experimental Research Unit. Animals were housed in standard polycarbonate cages (2-3 rats per cage) under controlled conditions: 12:12-hr light-dark cycles (lights on 07:00-19:00 h), temperature $21 \pm 1^{\circ} \mathrm{C}$, and relative humidity $55 \pm 5 \%$. They had access to standard chow food and tap water ad libitum. All male rats used in this study received two or three sexual behavior tests before starting the experiments. Accordingly, the animals that ejaculated 2-3 times in a copulation test (30-min session) were considered sexually active (experienced) and selected for the study. The rats were randomly divided into 4 groups as follows: control (sedentary), exercise, stress, and stress+exercise groups ( $\mathrm{n}=10$, for each group).

\section{Treadmill exercise procedure}

The schema of the experimental protocol in the present study is demonstrated in Figure 1. The animals in exercise and stress +exercise groups were forced to run on a 5-channels treadmill apparatus (May TME 0805, St. Louis, Missouri, MO, USA) at $0^{\circ}$ inclination in the exercise room during the light phase (10:00-13:30 h) for a total of 33 days of the experimental periods (moderate intensity). Running time and speed gradually increased from $15 \mathrm{~min}$ at $15 \mathrm{~m} / \mathrm{min}$ to $50 \mathrm{~min}$ at $25 \mathrm{~m} / \mathrm{min}$ during the experiment ( 5 days/week and except on the day of sexual behavior tests) on the basis of the procedure in Kim et al. (2011) with slight modifications. During the exercise training, the animals rarely received a mild electric shock (0.2-0.5 mA) through the grid located just behind the treadmill apparatus to motivate animals to run constantly. After completion of the daily exercise training, animals were placed back in their home cage. The treadmill apparatus was cleaned with $70 \%$ ethanol solution after each rat's exercise training. 


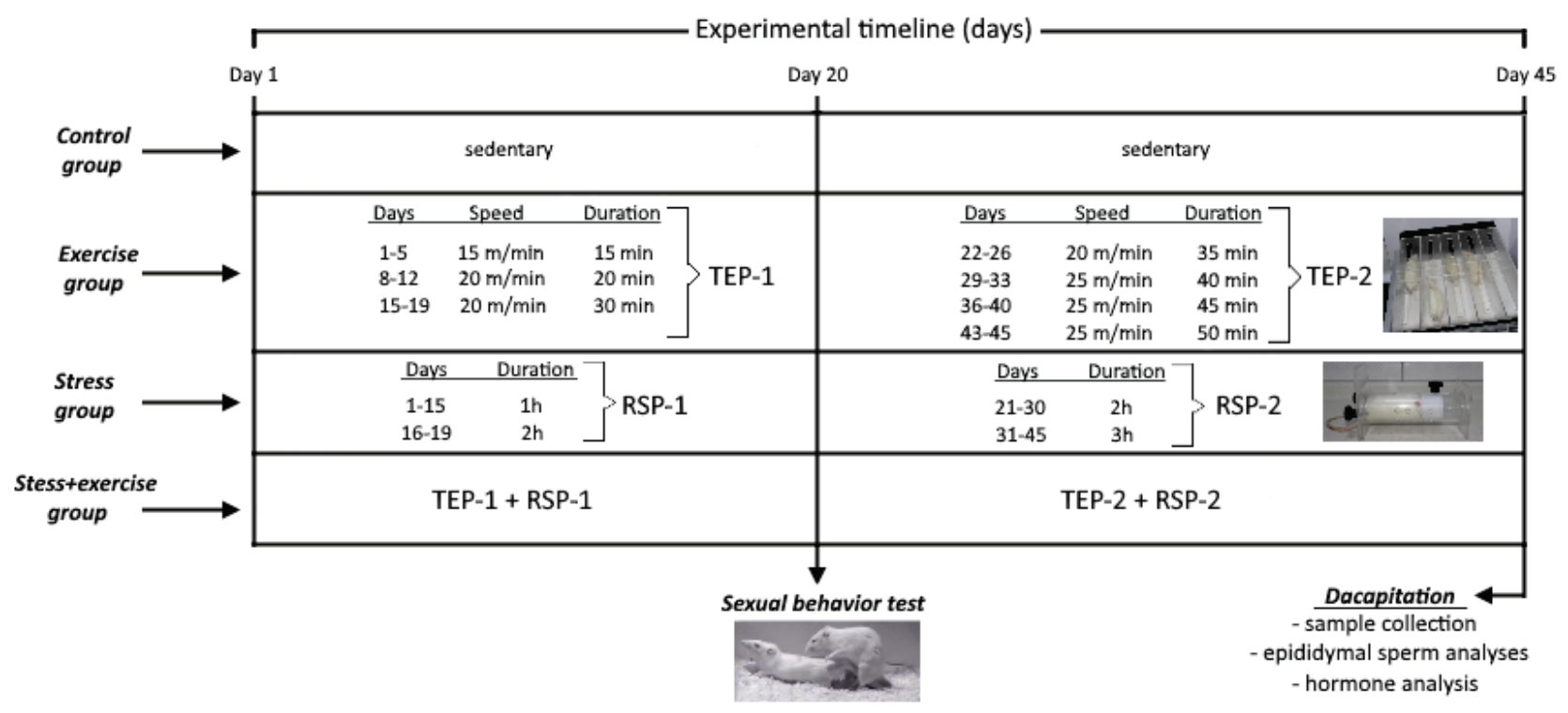

Fig 1. Schematic presentation of the experimental design. TEP: Treadmill Exercise Procedure and RSP: Restraint Stress Procedure.

\section{Restraint stress procedure}

All rats in stress and stress+exercise groups were subjected to chronic restraint stress for 45 days (except on the day of sexual behavior tests). Restraint stress was performed with clear plastic rat restrainers in a different room than the housing room of animals in normal room light (14:00-17:00 h). The rats were individually placed in the restrainers, and therefore restrained rats were allowed to breathe freely while their forward or backward movements were prevented (Wisłowska-Stanek et al. 2013). Animals were restrained daily for $1 \mathrm{~h}$ in the first 15 days, $2 \mathrm{~h}$ in the following 15 days, and $3 \mathrm{~h}$ in the last 15 days of the experiment. The animals were returned to their own cage after the daily stress procedure was completed, and the restrainer was cleaned and dried after each rat. Rats in the control group (sedentary rats) were not subjected to treadmill exercise or restraint stress during the experiment.

\section{Sexual behavior testing procedure}

To determine the effects of chronic exercise and/or stress on the sexual behavior of the male rats, sexual behavior test was conducted on all animals on the $20^{\text {th }}$ day of the experimental studies as described in Canpolat et al. (2016) and Yardimci et al. (2020). Stimulus ovariectomized females used in the sexual behavior tests were brought into sexual receptivity by subcutaneous injections of estradiol benzoate (10 $\mu \mathrm{g} / \mathrm{rat} / 0.1 \mathrm{ml}$ sesame oil), (Sigma Chemical Co, St. Louis, Missouri, MO, USA) and progesterone (500 $\mu \mathrm{g} / \mathrm{rat} / 0.1 \mathrm{ml}$ sesame oil), (Sigma Chemical Co,
St. Louis, Missouri, MO, USA) 48 and $4 \mathrm{~h}$ before the mating sessions, respectively (Jones et al. 2013).

All sexual behavior tests were performed in a test room during the reversed dark phase (14:00-16:00 $\mathrm{h}$, under dim red light). On test day, male rats were individually placed to an empty Plexiglas testing cage $(40 \times 40 \times 40 \mathrm{~cm})$ in order to habituate the environment for $10 \mathrm{~min}$. Thereafter, the sexually receptive female rat was introduced in the testing cage and sexual behavior test for each animal was carried out for $30 \mathrm{~min}$. All sexual behavior tests were recorded and later scored by an observer blinded to the experimental conditions. During the 30-min test, the following parameters were recorded: mount frequency (MF; the number of mounts before the first ejaculation), intromission frequency (IF; the number of intromissions before the first ejaculation); ejaculation frequency (EF; the number of ejaculations during the test period), mount latency (ML; latency from the introduction of the female to the first mount), intromission latency (IL; latency from the introduction of the female to the first intromission), ejaculation latency (EL; latency from the first intromission/mount to the first ejaculation), total mount frequency (MFT; the number of mounts during the test period), total intromission frequency (IFT; the number of intromissions during the test period), and postejaculatory interval (PEI; latency from the first ejaculation to the next intromission).

\section{Sample collection}

At the end of the experiment ( 45 days), after the last restraint stress session was completed, animals were 
anesthetized with an intramuscular injection of ketaminexylazine, and then decapitated. Following decapitation, trunk blood was immediately collected and centrifuged at $+4{ }^{\circ} \mathrm{C}$ (5 min at $\left.4000 \mathrm{rpm}\right)$, and the serum samples were stored at $-20{ }^{\circ} \mathrm{C}$ until hormone analysis. The reproductive organs of rats including testis, epididymis, prostate, and seminal vesicle were removed, cleared from adhering connective tissue, and weighed as wet. Immediately after weighing the epididymis, the content of the right and left epididymis was used for epididymal sperm analyses.

\section{Epididymal sperm analyses}

Epididymal sperm concentration, sperm motility, and sperm morphology were determined by using the modified methods described by Türk et al. (2008). In brief, the epididymal sperm concentration in the right epididymis was counted with a hemocytometer. The percentage of forward progressive sperm motility in freshly isolated left cauda epididymis was evaluated using a light microscope with heated stage. The sperm morphologic examination was also performed in the left cauda epididymis. After preparing the slides stained with eosin-nigrosin (1.67\% eosin, $10 \%$ nigrosine, and $0.1 \mathrm{M}$ sodium citrate), all slides were viewed under a light microscope at $400 \times$ magnification for assessment of morphologically abnormal sperm. Finally, a total of 300 spermatozoa were examined on each slide ( 3000 cells in each group). The head, tail, and total abnormality rates of spermatozoa were expressed in percentages.

\section{Hormone analysis}

The serum luteinizing hormone (LH), testosterone, and corticosterone levels were measured by enzyme-linked immunosorbent assay (ELISA) method using the commercial rat-specific ELISA kits provided by SunRed Biological Technology Company (Shanghai, China). Serum LH levels (Cat. No: 201-11-0180; sensitivity: $\quad 0.206 \mathrm{mIU} / \mathrm{ml}$; and detection range of 0.3-60 mIU/ml), serum testosterone levels (Cat. No: 201-11-5126; sensitivity: $8.775 \mathrm{pg} / \mathrm{ml}$; and detection range of $10-3000 \mathrm{pg} / \mathrm{ml}$ ), and serum corticosterone levels (Cat. No: SRB-T-87473; sensitivity: $5.005 \mathrm{ng} / \mathrm{ml}$; and detection range of $6-1000 \mathrm{ng} / \mathrm{ml}$ ) were detected in accordance with the manufacturer's instructions. Concentrations were measured at $450 \mathrm{~nm}$ with an ELISA reader (Thermo Scientific, Waltham, Massachusetts, MA, USA).

\section{Statistical analysis}

The statistical analyses were performed by SPSS software, version 22 for Windows. All data were presented as mean \pm standard error of mean (SEM) or in percentage and $p<0.05$ was considered statistically significant. One-way analysis of variance (ANOVA), followed by post hoc Tukey's test was used to determine the differences among the groups in terms of all behavioral data, sperm characteristics (sperm concentration and motility), hormone levels, and reproductive organ weights. In addition, abnormal sperm morphology rates were analyzed with the Pearson Chi-square test.

\section{Results}

Effects of chronic exercise and/or stress on sexual behavior

Table 1 shows the effects of chronic exercise and/or stress on sexual behavior parameters in male rats when compared to the control group. It was observed that there was no statistically significant difference in mount responses (MF, ML, and MFT) in the exercise, stress, or stress+exercise group when compared to the control group. Similarly, no change was seen for intromission responses (IF, IL, and IFT) in both exercise group and stress plus exercise group in comparison to the sedentary rats. On the other hand, only restraint stress caused a significant increase in IF ( $p<0.05$, Table 1$)$, while it did not change IL and IFT. Regarding ejaculation responses, only treadmill exercise or only restraint stress did not alter the EF of rats compared to sedentary rats. However, restraint stress combined with treadmill exercise significantly increased the EF when compared to the stress group $(p<0.05$, Table 1$)$. Treadmill exercise, restraint stress or restraint stress combined with treadmill exercise did not statistically affect the EL compared with the sedentary group. When compared to the sedentary rats, rats in both exercise group and stress plus exercise groups had a shorter PEI, which were found to be statistically significant ( $p<0.05$ and $p<0.01$, respectively, Table 1). However, it was determined that only restraint stress had no effect on the PEI of rats when compared to the control group.

Effects of chronic exercise and/or stress on sperm parameters

The spermatological findings in all groups are given in Table 2. Both treadmill exercise and restraint 
stress combined with treadmill exercise did not significantly affect the epididymal sperm concentration, sperm motility, and abnormal sperm rates compared to the control group. On the other hand, sperm parameters were negatively affected by the restraint stress, and consequently, sperm concentration and sperm motility significantly decreased $\quad(p<0.05$ and $p<0.001$, respectively) while the tail and total abnormality rates of spermatozoa significantly increased $(p<0.05$, Table 2$)$ compared to the control group. In addition, significantly decreased sperm motility in rats receiving restraint stress increased significantly with treadmill exercise in rats receiving stress plus exercise $(p<0.001$, Table 2$)$.

Table 1. Effects of chronic exercise and/or stress on parameters of male sexual behavior. Data are expressed as mean \pm SEM. $* p<0.05$ and $* * p<0.01$; when compared to control group and ${ }^{*} p<0.05$; when compared to stress group (one-way ANOVA followed by post hoc Tukey's test, $\mathrm{n}=10$ for each group).

\begin{tabular}{lcccc}
\hline Parameters & Control & Stress & Exercise & Stress+Exercise \\
\hline$M F$ & $4.8 \pm 0.8$ & $10.3 \pm 3.8$ & $7.5 \pm 1.6$ & $6.2 \pm 1.3$ \\
$I F$ & $11.9 \pm 1.5$ & $21.3 \pm 3.3^{*}$ & $18.4 \pm 1.6$ & $17.2 \pm 1.3$ \\
$E F$ & $2 \pm 0$ & $1.8 \pm 0.3$ & $2.5 \pm 0.2$ & $2.6 \pm 0.2^{\#}$ \\
$M L(s)$ & $84.9 \pm 31.6$ & $132.6 \pm 43.3$ & $69.8 \pm 18.7$ & $93.4 \pm 32$ \\
$I L(s)$ & $23.4 \pm 6.6$ & $32.9 \pm 9$ & $24.4 \pm 8.3$ & $20.6 \pm 5.8$ \\
$E L(s)$ & $354.1 \pm 63.3$ & $527.6 \pm 93.9$ & $501.7 \pm 66.8$ & $419.4 \pm 51.1$ \\
$M F T$ & $13 \pm 2$ & $15.9 \pm 3.5$ & $14.5 \pm 2.5$ & $15.5 \pm 2.6$ \\
$I F T$ & $27.2 \pm 2.7$ & $34.9 \pm 4.6$ & $34.5 \pm 3.9$ & $36.5 \pm 4.1$ \\
$P E I(s)$ & $494.1 \pm 31.8$ & $392.9 \pm 22.5$ & $367.7 \pm 29.8^{*}$ & $353.6 \pm 31.2^{* *}$ \\
\hline
\end{tabular}

Table 2. Effects of chronic exercise and/or stress on sperm characteristics in rats. Data are expressed as mean \pm SEM or in percentage. $* p<0.05$ and $* * p<0.001$; when compared to control group and ${ }^{*} p<0.001$; when compared to stress group (one-way ANOVA followed by post hoc Tukey's test or Pearson Chi-square test, $n=10$ for each group).

\begin{tabular}{lcccc}
\hline Variable & Control & Stress & Exercise & Stress+Exercise \\
\hline Sperm concentration $\left(10^{6} / \mathrm{ml}\right)$ & $145.3 \pm 11.6$ & $109.9 \pm 8^{*}$ & $137.5 \pm 8.5$ & $142.5 \pm 8.6$ \\
Sperm motility $(\%)$ & $65.5 \pm 2.3$ & $36.3 \pm 1.8^{* *}$ & $55.6 \pm 4.2$ & $59.3 \pm 4.6^{\#}$ \\
\hline Abnormal sperm rate $(\%)$ & & & & \\
\hline Head & 5 & 7 & 6 & 6 \\
Tail & 4 & $13^{*}$ & 5 & 9 \\
Total & 9 & $20^{*}$ & 11 & 15 \\
\hline
\end{tabular}

Effects of chronic exercise and/or stress on serum levels of LH, testosterone, and corticosterone

Chronic restraint stress significantly decreased serum LH levels compared to the control group $(\mathrm{mIU} / \mathrm{ml}$; control group: $3 \pm 0.1$ and stress group: $2.7 \pm 0.1, p<0.05$, Fig. 2A). However, serum LH levels were not affected by treadmill exercise or restraint stress combined with treadmill exercise when compared to the control group (Fig. 2A). The serum testosterone levels were significantly increased in the exercise group $(\mathrm{pg} / \mathrm{ml}$; control group: $118.4 \pm 1.9$ and exercise group: $134.9 \pm 1.7$, $p<0.001$, Fig. 2B), whereas they did not change in the stress group or stress+exercise group compared with the control group (Fig. 2B). The exercise group and the stress group had significantly higher serum corticosterone levels than the sedentary rats $(\mathrm{ng} / \mathrm{ml}$; control group: $55.5 \pm 1.2$, exercise group: $63.3 \pm 1.3$, and stress group: $64.3 \pm 1.5 ; p<0.01$ for exercise group and $p<0.001$ for stress group, Fig. 2C). On the other hand, the stress +exercise group did not differ significantly from the control group in terms of serum corticosterone levels (Fig. 2C). 
Effects of chronic exercise and/or stress on reproductive organ weights

Treadmill exercise, restraint stress or restraint stress combined with treadmill exercise did not significantly change the absolute weights of testis, epididymis, prostate, and seminal vesicle compared to the control group (Table. 3).
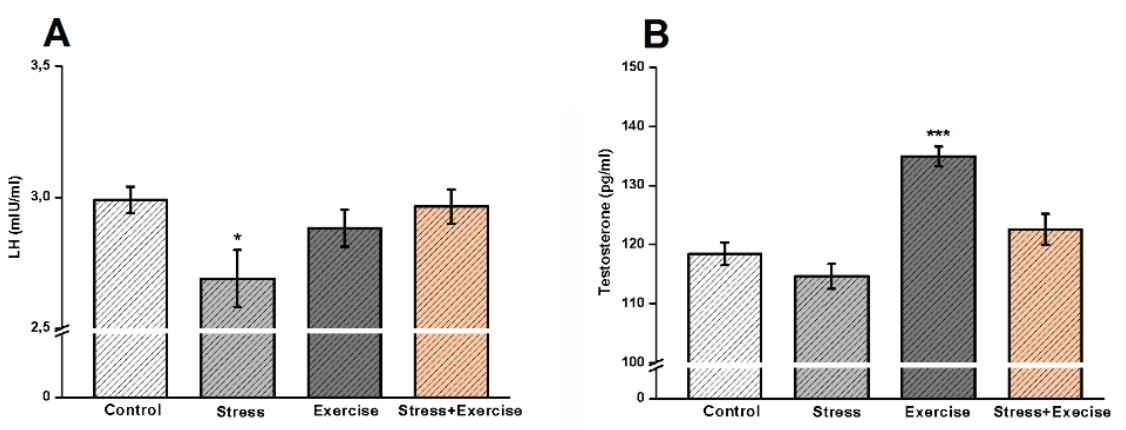

Fig 2. Effects of chronic exercise and/or stress on serum hormone levels in rats. (A) Serum LH levels. (B) Serum testosterone levels. (C) Serum corticosterone levels. Data are expressed as mean \pm SEM. $* p<0.05, * * p<0.01$, and $* * * p<0.001$; when compared to control group (one-way ANOVA followed by post hoc Tukey's test, $\mathrm{n}=10$ for each group).

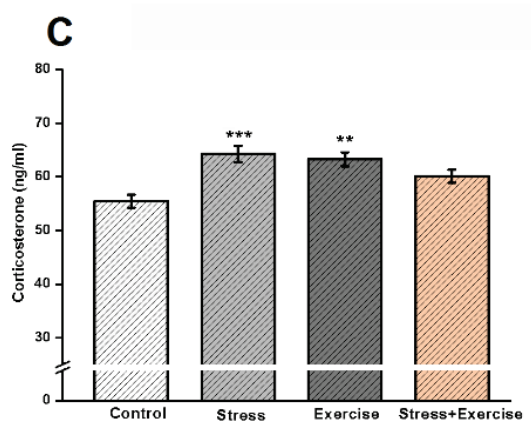

Table 3. Effects of chronic exercise and/or stress on absolute reproductive organ weights. Data are expressed as mean \pm SEM (one-way ANOVA followed by post hoc Tukey's test, $\mathrm{n}=10$ for each group).

\begin{tabular}{lcccc}
\hline Variable & Control & Stress & Exercise & Stress+Exercise \\
\hline $\begin{array}{l}\text { Testis }(g) \\
\text { Left }+ \text { right } / 2)\end{array}$ & $1.4 \pm 0.04$ & $1.24 \pm 0.04$ & $1.42 \pm 0.04$ & $1.33 \pm 0.03$ \\
Epididymis $(g)$ & $0.56 \pm 0.01$ & $0.54 \pm 0.01$ & $0.54 \pm 0.01$ & $0.52 \pm 0.02$ \\
Left + right/2) & $0.5 \pm 0.02$ & $0.44 \pm 0.01$ & $0.44 \pm 0.03$ & $0.4 \pm 0.05$ \\
Prostate $(g)$ & $0.73 \pm 0.02$ & $0.84 \pm 0.07$ & $0.83 \pm 0.03$ & $0.71 \pm 0.03$ \\
Seminal vesicle $(g)$ & & & \\
\hline
\end{tabular}

\section{Discussion}

The effects of chronic exercise and/or stress on serum LH, testosterone and corticosterone levels, and sexual behavior

The effects of chronic treadmill exercise on chronically-stressed male rats' serum LH, testosterone, corticosterone levels, and sexual behavior were revealed, for the first time, in this study. Chronic restraint stress significantly decreased LH levels in the stress group while there was no change in LH levels in other groups. This result is in agreement with that chronic restraint stress in rats leads to a reduction in the hypothalamic corticotropin-releasing hormone (CRH) level, a rise in plasma levels of adrenocorticotropic hormone (ACTH) and glucocorticoids, as well as a general suppressing effect on the hypothalamic-pituitary-gonadal axis (HPG), by declining testosterone and LH (Retana-Márquez et al. 2003). However, in our study, there was no change in testosterone levels in the stress group, and such an effect may depend on the type and duration of the chronic restraint stress protocol (Retana-Márquez et al. 2014). On the other hand, chronic treadmill exercise significantly increased testosterone levels in only exercise group in accordance with the previous studies (Fry et al. 1998, Raastad et al. 2000, Linnamo et al. 2005, Izquierdo et al. 
2006). However, there was no change in testosterone levels in stress and stress+exercise groups. It has been reported that the changes in androgenic response are not always relevant to varied LH levels (Andersen et al. 2004), and hence, our testosterone result may not have changed for such a reason. Concerning corticosterone levels, it significantly increased in both stress and exercise groups. Increased corticosterone levels in the stress group confirmed the activation of the HPA axis by restraint stress (Retana-Márquez et al. 2014). In addition, unexpected increase in corticosterone levels in the exercise group may have resulted from exercise protocol causing sensitization of the HPA axis response. Some studies have indicated that treadmill exercise may act as a stressor activating the HPA axis (Contarteze et al. 2008, Radahmadi et al. 2017). Therefore, it has been suggested in the literature that voluntary wheel running has an advantage over treadmill exercise since it needs only minimal researcher intervention and does not require aversive stimuli (e.g. electric shocks) to motivate the animals to run (Poole et al. 2020). Nevertheless, we preferred to use treadmill exercise rather than voluntary wheel running as treadmill exercise in rats permits calculation and setting of external work and work rate as well as intensity and duration (Poole et al. 2020). Also, the animal has control over the quantity, intensity, and timing of its running behavior in the voluntary wheel running, which is variable and also may change on a large scale among animals (Poole et al. 2020).

Concerning the effects of chronic stress on sexual behavior in male rats, chronic restraint stress is known to disrupt sexual behavior parameters involving ML, IL, EL, and PEI (Brotto et al. 2001). However, whether chronic treadmill exercise may positively influence the effects of chronic stress on sexual behavior is not known. In our study, we demonstrated that chronic restraint stress decreased sexual activity by increasing IF in agreement with the increase of IF, which may be considered as the sign of weakening of sexual activity (Grønli et al. 2005). It seems that a decrease in sexual activity by increased IF may be due to other stress-related mechanisms in the brain since sexual behavior is suggested to be not affected by the increase in corticosterone nor decrease in testosterone (Retana-Márquez et al. 2009). Also supporting this situation, one study has shown that stress can inhibit the consummatory part (including intromission) (Paredes et al. 1999) of male rat sexual behavior by increasing endogenous opioids, especially beta-endorphin (RetanaMárquez et al. 2014).
On the other hand, EF was significantly improved in the stress+exercise group compared to the stress group. Chronic treadmill exercise is suggested to increase sexual performance by increasing EF in previous studies in a similar way (Chaturapanich et al. 2012, Lee et al. 2018). Retana-Márquez et al. (2003) reported that testosterone propionate treatment could not prevent the effects of stress on sexual behavior in castrated male rats even though the levels of testosterone were high in the treated animal. Male sexual behavior is known to be under the control of central neural mechanisms and testosterone (Chaturapanich et al. 2012). However, in our study, improved sexual performance by increased EF may be related to central mechanisms rather than testosterone since there is no change in testosterone levels in the stress+exercise group.

Exercise and stress+exercise groups had significantly lower PEI compared to the control group. The PEI has been assessed as libido, index of potency, and the rate of recovery from exhaustion after the first series of mating (Yakubu and Akanji 2011). A PEI of more than $5400 \mathrm{~s}$ shows that the male is sexually tired, and the intensity of sexual behavior will be diminished in subsequent mating (Yakubu and Akanji 2011). Therefore, the significantly decreased PEI at exercise and stress+exercise indicated that treadmill exercise increased potency or libido while chronic restraint stress did not affect this parameter. Damassa et al. (1977) showed that there was no relationship between the circulating plasma testosterone levels and PEI in intact as well as castrated rats. Therefore, PEI may have changed independently of testosterone in our study.

The effects of chronic exercise and/or stress on sperm parameters and reproductive organ weights

Chronic restraint stress significantly decreased sperm concentration and motility and increased abnormal-tail and abnormal total sperm rate. To our knowledge, chronic treadmill exercise improved sperm motility in the stress+exercise group compared to the stress group for the first time in this study. However, chronic treadmill exercise did not affect sperm concentration and sperm morphology in the exercise or stress+exercise group. Chronic restraint stress was found to decrease sperm count (Hari Priya and Reddy 2012, Arun et al. 2016a, Arun et al. 2016b), motility (Hari Priya and Reddy 2012, Ribeiro et al. 2018), and increase abnormal sperm rate (Arun et al. 2016a, Arun et al. 2016b) in previous studies. Chronic restraint stress 
reduces testosterone release by inhibiting LH secretion (Nirupama et al. 2013a). The decrease in sperm concentration and motility may result from the decrease in testosterone levels in rats exposured to chronic restraint stress (Arun et al. 2016a, Ribeiro et al. 2018). However, there was no change in testosterone levels in the stress group in our study. Therefore, another possible mechanism may be that oxidative stress have a role in the deterioration of sperm parameters in the stress group. Arisha et al. (2019) reported that oxidative stress may lead to an increase of morphological abnormalities and a decrease in sperm concentration and motility as a result. To our knowledge, there is no mechanism of action explaining the effects of chronic restraint stress or chronic treadmill exercise on sperm parameters without affecting testosterone levels, which needs to be investigated in further studies.

Concerning the effects of chronic exercise and/or restraint stress on the male rats' reproductive organ weights, chronic restraint stress did not cause any change of reproductive organs' weights in the stress group, and chronic treadmill exercise has no effect on these organs' weights in the stress+exercise group in our study. Sexual accessory glands are known to be androgen-dependent, and thus testosterone is necessary for them to sustain their functionality (Retana-Márquez et al. 2014). As a result, the weights of these glands may decrease due to low levels of testosterone (Hari Priya and Reddy 2012). Also, the weight of the testis is dependent on testosterone (Nirupama et al. 2013b). It was reported that chronic restraint stress caused a significant decrease in testis and epididymis weights' as well as testosterone levels in previous studies (Hari Priya and Reddy 2012, Arun et al. 2016a, Arun et al. 2016b, Ribeiro et al. 2018). In addition, it was reported that seminal vesicles' weight did not change in the same studies (Hari Priya and Reddy 2012, Arun et al. 2016b), while it decreased in another study (Arun et al. 2016a). In addition, prostates' weight did not change in the chronic restraint stress group (Hari Priya and Reddy 2012). However, in our study, there was no change in testosterone levels in stress or stress+exercise groups in line with unchanged accessory organs' and testis weights in the stress or stress+exercise group. On the other hand, among the accessory sex organs, prostate and seminal vesicles are suggested to be the most sensitive reproductive parts to stress, but it is indicated that epididymal weights may decrease, and testis weights are usually not affected in the rat. Epididymal weights (absolute and relative to body weight) may decrease when testosterone level is low; however, epididymal weights are suggested as not sensitive, which may be an indicator as to the weights of the seminal vesicles and prostate. In the same study, it is emphasized that the effects of stress may be affected by several factors, involving the property of the stressor, period of the stress, species of animal. (Everds et al. 2013). By depending on these variables, our chronic restraint stress protocol may not have caused any changes in the weights of accessory sexual organs and testis.

In conclusion, chronic restraint stress may disrupt sexual behavior in terms of consummatory parameters of sexual behavior involving IF, and also sperm motility, and concentration. Furthermore, the ameliorative effect of chronic treadmill exercise on the disruption in sperm motility induced by chronic restraint stress has been revealed for the first time in this study. Since this study is based on an animal model, the present findings could partially reflect the characteristics of human sexual behavior. In addition, given the fact that the effects of stress include complex neuroendocrine mechanisms, further clinical studies are needed to clarify the effects of chronic stress on sexual behavior and reproductive parameters in men. Also, it can be concluded that treadmill exercise may also have a role as a stress factor. This is a methodological limitation that we will assess in further experiments.

\section{Conflict of Interest}

There is no conflict of interest.

\section{Acknowledgements}

The present study was supported by TUBITAK (The Scientific and Technological Research Council of Turkey) (Grant Nr.: 114S179).

\section{References}

AL-DAMEGH MA: Stress-induced changes in testosterone secretion in male rats: role of oxidative stress and modulation by antioxidants. Open J Anim Sci 4: 70-78, 2014. https://doi.org/10.4236/ojas.2014.42010 
ALMEIDA SA, PETENUSCI S, ANSELMO-FRANCI J, ROSA-E-SILVA A, LAMANO-CARVALHO T: Decreased spermatogenic and androgenic testicular functions in adult rats submitted to immobilization-induced stress from prepuberty. Braz J Med Biol Res 31: 1443-1448, 1998. https://doi.org/10.1590/S0100$\underline{879 X 1998001100013}$

ALMEIDA SA, PETENUSCI S, FRANCI JA, SILVA ARE, CARVALHO TL: Chronic immobilization-induced stress increases plasma testosterone and delays testicular maturation in pubertal rats. Andrologia 32: 7-11, 2000a. https://doi.org/10.1111/j.1439-0272.2000.tb02858.x

ALMEIDA SA, KEMPINAS WG, LAMANO CARVALHO TL: Sexual behavior and fertility of male rats submitted to prolonged immobilization-induced stress. Braz J Med Biol Res 33: 1105-1109, $2000 \mathrm{~b}$. https://doi.org/10.1590/S0100-879X2000000900019

ANDERSEN ML, BIGNOTTO M, MACHADO RB, TUFIK S: Different stress modalities result in distinct steroid hormone responses by male rats. Braz J Med Biol Res 37: 791-797, 2004. https://doi.org/10.1590/S0100$\underline{879 X 2004000600003}$

ARISHA AH, MOUSTAFA A: Potential inhibitory effect of swimming exercise on the Kisspeptin-GnRH signaling pathway in male rats. Theriogenology 133: 87-96, 2019. https://doi.org/10.1016/j.theriogenology.2019.04.035

ARUN S, BURAWAT J, SUKHORUM W, SAMPANNANG A, MANEENIN C, IAMSAARD S: Chronic restraint stress induces sperm acrosome reaction and changes in testicular tyrosine phosphorylated proteins in rats. Int J Reprod Biomed 14: 443-452, 2016 a.

ARUN S, BURAWAT J, SUKHORUM W, SAMPANNANG A, UABUNDIT N, IAMSAARD S: Changes of testicular phosphorylated proteins in response to restraint stress in male rats. J Zhejiang Univ Sci B 17: 21-29, 2016 b. https://doi.org/10.1631/jzus.B1500174

BAL E, MURAT N, DEMIR O, SONER BC, CAN E, GIDENER S, ESEN A: Restraint stress impairs erectile responses in rats. Tohoku J Exp Med 217: 239-242, 2009. https://doi.org/10.1620/tjem.217.239

BAO AM, MEYNEN G, SWAAB D: The stress system in depression and neurodegeneration: focus on the human hypothalamus. Brain Res Rev 57: 531-553, 2008. https://doi.org/10.1016/j.brainresrev.2007.04.005

BROTTO LA, GORZALKA BB, LAMARRE AK: Melatonin protects against the effects of chronic stress on sexual behaviour in male rats. Neuroreport 12: 3465-3469, 2001. https://doi.org/10.1097/00001756-200111160-00018

CANPOLAT S, ULKER N, YARDIMCI A, BULMUS O, OZDEMIR G, SAHIN Z, ERCAN Z, SERHATLIOGLU I, KACAR E, OZCAN M, TURK G, OZKAN Y, ATMACA M, YILMAZ B, KELESTIMUR H: Studies on the reproductive effects of chronic treatment with agomelatine in the rat. Eur $\mathrm{J}$ Pharmacol 770: 33-39, 2016. https://doi.org/10.1016/j.ejphar.2015.11.054

CHATURAPANICH G, CHAIYAKUL S, VERAWATNAPAKUL V, YIMLAMAI T, PHOLPRAMOOL C: Enhancement of aphrodisiac activity in male rats by ethanol extract of Kaempferia parviflora and exercise training. Andrologia 44: 323-328, 2012. https://doi.org/10.1111/j.1439-0272.2011.01184.x

CLARKE RN, KLOCK SC, GEOGHEGAN A, TRAVASSOS DE: Relationship between psychological stress and semen quality among in-vitro fertilization patients. Hum Reprod 14: 753-758, 1999. https://doi.org/10.1093/humrep/14.3.753

CONTARTEZE RVL, MANCHADO FDB, GOBATTO CA, DE MELLO MAR: Stress biomarkers in rats submitted to swimming and treadmill running exercises. Comp Biochem Physiol A Physiol 151: 415-422, 2008. https://doi.org/10.1016/j.cbpa.2007.03.005

DAMASSA DA, SMITH ER, TENNENT B, DAVIDSON JM: The relationship between circulating testosterone levels and male sexual behavior in rats. Horm Behav 8: 275-286, 1977. https://doi.org/10.1016/0018-506X(77)90002-2

DEMIRCI T, SAHIN E: The effect of chronic stress and obesity on sperm quality and testis histology in male rats; a morphometric and immunohistochemical study. Histol Histopathol 34: 287-302, 2019. https://doi.org/10.14670/HH-18-077

EVERDS NE, SNYDER PW, BAILEY KL, BOLON B, CREASY DM, FOLEY GL, ROSOL TJ, SELLERS T: Interpreting stress responses during routine toxicity studies: a review of the biology, impact, and assessment. Toxicol Pathol 41: 560-614, 2013. https://doi.org/10.1177/0192623312466452

FLORIO P, ZATELLI MC, REIS FM, DEGLI UBERTI EC, PETRAGLIA F: Corticotropin releasing hormone: a diagnostic marker for behavioral and reproductive disorders. Front Biosci 12: 551-560, 2007. https://doi.org/10.2741/2081 
FRY AC, KRAEMER WJ, RAMSEY LT: Pituitary-adrenal-gonadal responses to high-intensity resistance exercise overtraining. J Appl Physiol 85: 2352-2359, 1998. https://doi.org/10.1152/jappl.1998.85.6.2352

GARCÍA-DÍAZ EC, GÓMEZ-QUIROZ LE, ARENAS-RÍOS E, ARAGÓN-MARTÍNEZ A, IBARRA-ARIAS JA, RETANA-MÁRQUEZ MDSI: Oxidative status in testis and epididymal sperm parameters after acute and chronic stress by cold-water immersion in the adult rat. Syst Biol Reprod Med 61: 150-160, 2015. https://doi.org/10.3109/19396368.2015.1008071

GASKINS AJ, MENDIOLA J, AFEICHE M, JØRGENSEN N, SWAN SH, CHAVARRO JE: Physical activity and television watching in relation to semen quality in young men. Br J Sports Med 49: 265-270, 2015. https://doi.org/10.1136/bjsports-2012-091644

GRØNLI J, MURISON R, FISKE E, BJORVATN B, SØRENSEN E, PORTAS CM, URSIN R: Effects of chronic mild stress on sexual behavior, locomotor activity and consumption of sucrose and saccharine solutions. Physiol Behav 84: 571-577, 2005. https://doi.org/10.1016/j.physbeh.2005.02.007

HARI PRIYA P, REDDY PS: Effect of restraint stress on lead-induced male reproductive toxicity in rats. J Exp Zool A Ecol Genet Physiol 317: 455-465, 2012. https://doi.org/10.1002/jez.1738

IZQUIERDO M, IBANEZ J, GONZÁLEZ-BADILLO JJ, HÄKKINEN K, RATAMESS NA, KRAEMER WJ, FRENCH DN, ESLAVA J, ALTADILL A, ASIAIN X, GOROSTIAGA EM: Differential effects of strength training leading to failure versus not to failure on hormonal responses, strength, and muscle power gains. J Appl Physiol 100: 1647-1656, 2006. https://doi.org/10.1152/japplphysiol.01400.2005

JOHNSON EO, KAMILARIS TC, CHROUSOS GP, GOLD PW: Mechanisms of stress: a dynamic overview of hormonal and behavioral homeostasis. Neurosci Biobehav Rev 16: 115-130, 1992. https://doi.org/10.1016/S0149$\underline{7634(05) 80175-7}$

JONES SL, FARRELL S, GREGORY JG, PFAUS JG: Sensitization of sexual behavior in ovariectomized rats by chronic estradiol treatment. Horm Behav 64: 8-18, 2013. https://doi.org/10.1016/j.yhbeh.2013.04.012

JOSEPH AM, NGUYEN LD, WELTER A, DOMINGUEZ J, BEHNKE B, ADHIHETTY P: Mitochondrial adaptations evoked with exercise are associated with a reduction in age-induced testicular atrophy in Fischer-344 rats. Biogerontology 15: 517-534, 2014. https://doi.org/10.1007/s10522-014-9526-Z

KHOO J, TIAN HH, TAN B, CHEW K, NG CS, LEONG D, TEO RC, CHEN RY: Comparing effects of low- and high-volume moderate-intensity exercise on sexual function and testosterone in obese men. J Sex Med 10: 1823-1832, 2013. https://doi.org/10.1111/jsm.12154

KIM BS, KIM MY, LEEM YH: Hippocampal neuronal death induced by kainic acid and restraint stress is suppressed by exercise. Neuroscience 194: 291-301, 2011. https://doi.org/10.1016/j.neuroscience.2011.06.029

LAMINA S, OKOYE CG, DAGOGO TT: Therapeutic effect of an interval exercise training program in the management of erectile dysfunction in hypertensive patients. J Clin Hypertens (Greenwich) 11: 125-129, 2009. https://doi.org/10.1111/j.1751-7176.2009.00086.x

LEE JM, KIM TW, PARK HS, PARK SS, SHIN MS, SUNG YH, SEO TB, KIM YP: Effects of exercise on sexual function and central mechanism in the streptozotocin-induced diabetic rats. J Exerc Rehabil 14: 10-15, 2018. https://doi.org/10.12965/jer.1836072.036

LINNAMO V, PAKARINEN A, KOMI PV, KRAEMER WJ, HÄKKINEN K: Acute hormonal responses to submaximal and maximal heavy resistance and explosive exercises in men and women. J Strength Cond Res 19: 566-571, 2005. https://doi.org/10.1519/00124278-200508000-00014

MAIO G, SARAEB S, MARCHIORI A: Physical activity and PDE5 inhibitors in the treatment of erectile dysfunction: results of a randomized controlled study. J Sex Med 7: 2201-2208, 2010. https://doi.org/10.1111/j.1743$\underline{6109.2010 .01783 . \mathrm{x}}$

MALEKI BH, TARTIBIAN B: Long-term low-to-intensive cycling training: impact on semen parameters and seminal cytokines. Clin J Sport Med 25: 535-540, 2015. https://doi.org/10.1097/JSM.00000000000000122

NIRUPAMA M, DEVAKI M, NIRUPAMA R, YAJURVEDI HN: Chronic intermittent stress-induced alterations in the spermatogenesis and antioxidant status of the testis are irreversible in albino rat. J Physiol Biochem 69: 59-68, 2013a. https://doi.org/10.1007/s13105-012-0187-6

NIRUPAMA M, YAJURVEDI HN: Durational effects of chronic stress on the testicular damage and its reversibility in albino rat. Eur J Exp Biol 3: 229-239, 2013b. 
NORDKAP L, JENSEN TK, HANSEN ÅM, LASSEN TH, BANG AK, JOENSEN UN, BLOMBERG JENSEN M, SKAKKEBÆK NE, JØRGENSEN N: Psychological stress and testicular function: a cross-sectional study of 1,215 Danish men. Fertil Steril 105: 174-187, 2016. https://doi.org/10.1016/j.fertnstert.2015.09.016

PAREDES RG, VAZQUEZ B: What do female rats like about sex? Paced mating. Behav Brain Res 105: 117-127, 1999. https://doi.org/10.1016/S0166-4328(99)00087-X

POOLE DC, COPP SW, COLBURN TD, CRAIG JC, ALLEN DL, STUREK M, O'LEARY DS, ZUCKER IH, MUSCH TI: Guidelines for animal exercise and training protocols for cardiovascular studies. Am J Physiol Heart Circ Physiol 318: H1100-H1138, 2020. https://doi.org/10.1152/ajpheart.00697.2019

RAASTAD T, BJØRO T, HALLEN J: Hormonal responses to high-and moderate-intensity strength exercise. Eur J Appl Physiol 82: 121-128, 2000. https://doi.org/10.1007/s004210050661

RADAHMADI M, ALAEI H, SHARIFI MR, HOSSEINI N: Stress biomarker responses to different protocols of forced exercise in chronically stressed rats. J Bodyw Mov Ther 21: 63-68, 2017. https://doi.org/10.1016/j.jbmt.2016.05.002

RETANA-MÁRQUEZ S, BONILLA-JAIME H, VAZQUEZ-PALACIOS G, MARTINEZ-GARCIA R, VELÁZQUEZMOCTEZUMA J: Changes in masculine sexual behavior, corticosterone and testosterone in response to acute and chronic stress in male rats. Horm Behav 44: 327-337, 2003. https://doi.org/10.1016/j.yhbeh.2003.04.001

RETANA-MÁRQUEZ S, BONILLA-JAIME H, VÁZQUEZ-PALACIOS G, MARTÍNEZ-GARCÍA R: Naltrexone effects on male sexual behavior, corticosterone, and testosterone in stressed male rats. Physiol Behav 96: 333-342, 2009. https://doi.org/10.1016/j.physbeh.2008.10.022

RETANA-MÁRQUEZ S, VIGUERAS-VILLASEÑOR RM, JUÁREZ-ROJAS L, ARAGÓN-MARTÍNEZ A, TORRES GR: Sexual behavior attenuates the effects of chronic stress in body weight, testes, sexual accessory glands, and plasma testosterone in male rats. Horm Behav 66: 766-778, 2014. https://doi.org/10.1016/j.yhbeh.2014.09.002

RIBEIRO CT, DE SOUZA DB, COSTA WS, SAMPAIO FJ, PEREIRA-SAMPAIO MA: Immediate and late effects of chronic stress in the testes of prepubertal and adult rats. Asian J Androl 20: 385-390, 2018. https://doi.org/10.4103/aja.aja_68_17

ROSETY-RODRIGUEZ M, ROSETY J, FORNIELES G, ROSETY M, DIAZ A, ROSETY I, RODRÍGUEZ-PAREJA A, ROSETY M, ORDONEZ FJ, ELOSEGUI S: Home-based treadmill training improved seminal quality in adults with type 2 diabetes. Actas Urol Esp 38: 589-593, 2014. https://doi.org/10.1016/j.acuroe.2014.03.008

ROSMOND R, BJORNTORP P: The hypothalamic-pituitary-adrenal axis activity as a predictor of cardiovascular disease, type 2 diabetes and stroke. J Intern Med 247: 188-197, 2000. https://doi.org/10.1046/j.1365-2796.2000.00603.x

SATO K, IEMITSU M: Exercise and sex steroid hormones in skeletal muscle. J Steroid Biochem Mol Biol 145: 200-205, 2015. https://doi.org/10.1016/j.jsbmb.2014.03.009

TURK G, SONMEZ M, AYDIN M, YUCE A, GÜR S, YUKSEL M, AKSU EH, AKSOY H: Effects of pomegranate juice consumption on sperm quality, spermatogenic cell density, antioxidant activity and testosterone level in male rats. Clin Nutr 27: 289-296, 2008. https://doi.org/10.1016/j.clnu.2007.12.006

WISŁOWSKA-STANEK A, LEHNER M, SKÓRZEWSKA A, KRZĄŚCIK P, MACIEJAK P, SZYNDLER J, ZIEMBA A, PŁAŹNIK A: Changes in the brain expression of alpha-2 subunits of the GABA-A receptor after chronic restraint stress in low-and high-anxiety rats. Behav Brain Res 253: 337-345, 2013. https://doi.org/10.1016/j.bbr.2013.07.042

YAKUBU MT, AKANJI MA: Effect of aqueous extract of Massularia acuminata stem on sexual behaviour of male Wistar rats. Evid Based Complement Alternat Med 2011: 738103, 2011. https://doi.org/10.1155/2011/738103

YARDIMCI A, AKKOC RF, TEKTEMUR A, ULKER N, TEKTEMUR NK, GUZEL EE, CANPOLAT S, OZAN IE: Chronic maternal tobacco smoke exposure and/or alpha-lipoic acid treatment causes long-term deterioration of testis and sexual behavior in adult male rats. J Sex Med 17: 1835-1847, 2020. https://doi.org/10.1016/j.jsxm.2020.07.002

YOU T, DISANZO BL, ARSENIS NC: Aerobic exercise training attenuates obesity-related hypogonadism in male rats. Med Sci Sports Exerc 45: 1244-1251, 2013. https://doi.org/10.1249/MSS.0b013e318285816c 